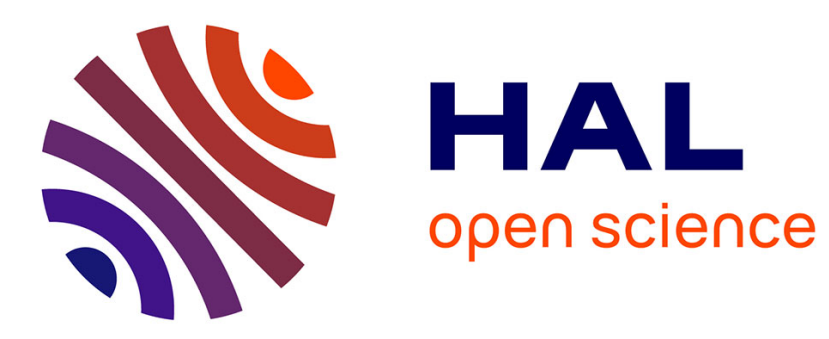

\title{
Some controversial points related to transport in microcrystalline silicon.
}

\author{
J Kocka, Alex Vetushka, Antonin Fejfar
}

\section{To cite this version:}

J Kocka, Alex Vetushka, Antonin Fejfar. Some controversial points related to transport in microcrystalline silicon.. Philosophical Magazine, 2009, 89 (28-30), pp.2557-2571. 10.1080/14786430903025724 . hal-00519090

\section{HAL Id: hal-00519090 \\ https://hal.science/hal-00519090}

Submitted on 18 Sep 2010

HAL is a multi-disciplinary open access archive for the deposit and dissemination of scientific research documents, whether they are published or not. The documents may come from teaching and research institutions in France or abroad, or from public or private research centers.
L'archive ouverte pluridisciplinaire HAL, est destinée au dépôt et à la diffusion de documents scientifiques de niveau recherche, publiés ou non, émanant des établissements d'enseignement et de recherche français ou étrangers, des laboratoires publics ou privés. 


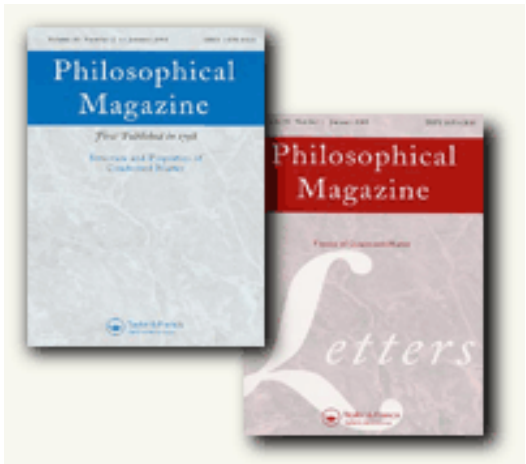

\section{Some controversial points related to transport in microcrystalline silicon.}

\begin{tabular}{|c|c|}
\hline Journal: & Philosophical Magazine \& Philosophical Magazine Letters \\
\hline Manuscript ID: & TPHM-08-Sep-0338.R1 \\
\hline Journal Selection: & Philosophical Magazine \\
\hline $\begin{array}{r}\text { Date Submitted by the } \\
\text { Author: }\end{array}$ & 10-Apr-2009 \\
\hline Complete List of Authors: & $\begin{array}{l}\text { Kocka, J; Institute of Physics, v.v.i., Academy of Sciences of the } \\
\text { Czech Republic } \\
\text { Vetushka, Alex; Institute of Physics, v.v.i., Academy of Sciences of } \\
\text { the Czech Republic } \\
\text { Fejfar, Antonin; Institute of Physics, v.v.i., Academy of Sciences of } \\
\text { the Czech Republic }\end{array}$ \\
\hline Keywords: & grain boundaries, microcrystalline silicon, transport properties \\
\hline Keywords (user supplied): & grain boundaries, microcrystalline silicon, transport properties \\
\hline
\end{tabular}

\section{S) ScholaroNE \\ Manuscript Central}




\title{
Some controversial points related to transport in microcrystalline silicon.
}

\author{
J. Kočka, A. Vetushka and A. Fejfar \\ Institute of Physics, Academy of Sciences of the Czech Republic, \\ Cukrovarnická 10, 16253 Praha 6, Czech Republic \\ kocka@fzu.cz
}

\begin{abstract}
We have compared the results of effective medium theories with the d.c. dark electrical conductivity for a number of undoped thin film Si series crossing the amorphous/microcrystalline transition. All series exhibited the percolation threshold at $70-80 \%$ crystallinity, i.e., at values higher than expected for a random mixture. We explain this observation by a resistive coating of the crystalline grains, which presents a limiting step for transport. We identify this coating with the Large Grain Boundaries (LGB) from our previously formulated model of transport. The LGBs consist of an amorphous $\mathrm{Si}$ based tissue with a band gap increased due to $\mathrm{H}$ and $\mathrm{O}$ alloying, to which also most of the defects concentrate. The apparent paradox of higher room temperature conductivity resulting from the formation of LGBs is explained, too. Our microscopic measurements of conductivity with an AFM tip are consistent with this model if care is taken to avoid artifacts related to tip induced oxidation of the sample surface.
\end{abstract}

Keywords: electronic transport, microcrystalline silicon, grain boundaries.

\section{Introduction}

Crystalline silicon (c-Si) is the dominant material of the present microelectronics and even photovoltaic industry. The supreme role of c-Si can be challenged by its counterpart - amorphous hydrogenated silicon (a-Si:H) in photovoltaics, mainly because a-Si:H can be produced relatively cheaply at low temperatures on large area of almost any substrate, including plastics. There are many forms of silicon in between - polycrystalline silicon, microcrystalline silicon $(\mu \mathrm{c}-\mathrm{Si}: \mathrm{H})$ or nanocrystalline silicon (nc-Si:H), which are being intensely studied in order to combine the advantages of c-Si and a-Si:H. However, the common characteristic feature of these materials is the presence of grain boundaries and a very complex microstructure.

For example, a great advantage of $\mu \mathrm{c}-\mathrm{Si}: \mathrm{H}$ is its stability against light soaking, important for the use in photovoltaic solar cells [1]. Both a-Si:H and $\mu \mathrm{c}-\mathrm{Si}: \mathrm{H}$ can be prepared by plasma enhanced chemical vapor deposition (PE CVD) and the a-Si:H / $\mu \mathrm{c}-\mathrm{Si}: \mathrm{H}$ transition can be achieved just by a change of any of the deposition parameters like substrate temperature $\left(\mathrm{T}_{\mathrm{S}}\right)$, discharge frequency or hydrogen dilution $\left(\mathrm{r}_{\mathrm{H}}=\left[\mathrm{H}_{2}\right] /\left[\mathrm{SiH}_{4}\right]\right)$. The a-Si:H / $\mu \mathrm{c}-\mathrm{Si}: \mathrm{H}$ transition also often occurs during a single deposition while the film thickness increases.

On the basis of atomic force microscopy (AFM) combined with the local current mapping [2], electron spin resonance (ESR) $[3,4]$ and many other techniques it is generally believed that $\mu \mathrm{c}-\mathrm{Si}: \mathrm{H}$ is actually composed of at least two characteristic sizes of crystalline Si grains: the small ones (10 $30 \mathrm{~nm})$ and the large ones $(100-500 \mathrm{~nm})$, formed as aggregates (columns) from the small ones.

The small grains are connected by twin boundaries and stacking faults, preserving the tetrahedral coordination and so no defects are expected [5] at their boundaries. The $10-30 \mathrm{~nm}$ typical size of the small grains is not sufficient for the formation of the space-charge regions and potential barriers which could block the charge transport. Thus the main consequence of the existence of the small grain boundaries is the formation of the localized tail states.

However, there are many unsolved problems related to the Large Grains (LG), often forming columns within the a-Si:H tissue. Recently, the basic questions like "where is the dominant transport route" in $\mu \mathrm{c}-\mathrm{Si}: \mathrm{H}$, have been reopened [6]. In this reference [6] the authors performed a very valuable detailed analysis of a large number of experimental data. However, our results, they have 
been in a few cases misunderstood and interpreted in a way which differs from what we said. Moreover, the main conclusion [6] that the dominant transport route is in the "disordered tissue that encapsulates the crystalline columns" (we call this the Large Grain Boundaries - LGB), is based on experimental results which, as our experience tells us, have a different physical origin. This is why we feel it important to discuss these questions in detail again in this paper.

In part 2 we briefly comment on the experimental details for macroscopic and microscopic conductivity measurements and then, in part 3, our model of transport and its experimental basis are summarized. In part 4 we illustrate, using new AFM measurements, how AFM artifacts can lead to the incorrect conclusion that the LGBs represent the main transport route and in part 5 we explain what could have been the reasons for misunderstanding of our transport model and conductivity results.

\section{Experimental details}

In this paper we discuss mainly the electrical conductivity and AFM results. The details of the samples preparation are given in corresponding references. As concerns the conductivity, all results presented in this paper have been measured with the coplanar geometry, in which the transport parallel to the substrate is measured. When a few mm wide metal contacts are separated by a gap of about $1-4 \mathrm{~mm}$ and applied to about $1 \mu \mathrm{m}$ or thinner silicon layer, the contact resistance can be neglected and the true conductivity is evaluated.

For photovoltaic solar cells, the charge transport perpendicular to the substrate is important. However, in the corresponding sandwich geometry, the contact resistance cannot be neglected in the d.c. measurements. As we have shown [7], a possible solution is to use the a.c. conductivity, for which the influence of the contacts is excluded at sufficiently high frequencies and the true perpendicular conductivity can be evaluated.

We have confirmed the expected anisotropy of transport in $\mu \mathrm{c}-\mathrm{Si}: \mathrm{H}$ when the clear columnar structure is formed, in this way supporting the idea that the crystalline columns in their whole volume have much higher conductivity. This corresponds to the observed fact that the conductivity of alternating a-Si:H/ $\mu \mathrm{c}-\mathrm{Si}: \mathrm{H} / \mathrm{a}-\mathrm{Si}: \mathrm{H}$ multilayers [7,8] was clearly isotropic within a wide range of crystallinities, because the thin amorphous inter-layers interrupted the growth of the columns.

In order to study the local electronic properties of the grains or columns in $\mu \mathrm{c}-\mathrm{Si}: \mathrm{H}$, we have pioneered the use of AFM with a conductive cantilever as a probe of local conductivity [2]. Our first measurements were performed in the Omicron ultra-high vacuum (UHV) AFM on samples deposited in the attached chamber and transferred without breaking the vacuum in order to prevent surface oxidation. We were able to clearly identify the Si crystallites due to their higher conductivity when compared to the amorphous background. This allowed us to identify even the smallest crystallites and at that stage we did not discuss the absolute value of the AFM detected currents. Because the throughput of the samples through the UHV system was rather slow, we have shown that the same measurements can be performed in air [9] in an ambient AFM system (Veeco Dimension 3100). Although the current levels were substantially lower in air due to natural oxidation ( [9], see also below), they were sufficient for the identification of crystallites.

\section{Our model of transport and its experimental basis}

We have studied the transition from a-Si:H to $\mu \mathrm{c}-\mathrm{Si}: \mathrm{H}$ on many series of thin silicon films [1014], ranging from pure a-Si:H through the mixed phase samples at relatively sharp a-Si:H / $\mu \mathrm{c}-\mathrm{Si}: \mathrm{H}$ transition region to highly crystalline samples, called a "single phase" $\mu \mathrm{c}-\mathrm{Si}: \mathrm{H}$ by the authors of [6]. In this point, we agree with the authors of [6] that what is generally called $\mu \mathrm{c}-\mathrm{Si}: \mathrm{H}$ is actually a wide class of materials. This is also why we have studied the a-Si:H / $\mu \mathrm{c}-\mathrm{Si}: \mathrm{H}$ transition.

The changes of the room temperature dark coplanar conductivity $\left(\sigma_{\mathrm{D}}\right)$ upon crossing the a-Si:H / $\mu \mathrm{c}-\mathrm{Si}: \mathrm{H}$ transition are illustrated in Fig. 1 for several of our thin film Si series. The conductivity is plotted as a function of the crystallinity $\left(X_{c}\right)$ obtained by measuring the contributions of the 
amorphous and crystalline phase in the Raman scattering spectra [15]. Due to very different microstructure for different sample series, not only the onset but also the values of conductivities have certain spread, nevertheless, it can be seen that most points follow the same trend, indicated by the solid line as a guide to the eye in Fig. 1.

It is evident that at low crystallinity in undoped $\mu \mathrm{c}-\mathrm{Si}: \mathrm{H}$ no percolation threshold can be found at the usually expected value of $X_{c} \sim 33 \%$ for a random three-dimensional (3D) mixture of components, where it was actually observed in doped $\mu \mathrm{c}-\mathrm{Si}: \mathrm{H}$ [16] (marked by the dashed line in Fig. 1). Indeed, we have observed on many series [10-14] that the most pronounced changes of the conductivity during the a-Si:H / $\mu \mathrm{c}-\mathrm{Si}: \mathrm{H}$ transition occur near $\mathrm{X}_{\mathrm{c}} \sim 60 \%$ and the transition is completed at $\mathrm{X}_{\mathrm{c}} \sim 70-80 \%$.

How can we explain the dramatic increase of $\sigma_{D}$ in Fig. 1 and how is it related to our model of transport? We interpret the dramatic increase of $\sigma_{D}$ at $X_{c} \sim 70-80 \%$ as the percolation transition, corresponding to the interconnection of the LGs. However, the percolation threshold close to $80 \%$ crystallinity cannot be explained (see Fig. 2) by simple random mixtures of the conductive crystalline and resistive amorphous components, where the values of $33 \%$ and $50 \%$ are expected in 3D and 2D cases, respectively.

Some insight can be obtained by using the alternative effective medium theories shown by the lines in Fig. 2. An effective medium is defined as a homogeneous material of such properties that including it as a structural unit into the composite would not change the properties of the sample, i.e. in our case the conductivity. The lines in Fig. 2 were calculated using conductivities $5 * 10^{-11} \Omega^{-1}$ $\mathrm{cm}^{-1}$ and $10^{-3} \Omega^{-1} \mathrm{~cm}^{-1}$ for amorphous and crystalline components. The different mixing of the components is marked schematically above Fig. 2 and the arrows mark the model crystallinity at which the transition should occur. The dependence of the effective conductivity on the crystallinity for random mixtures of the two components was calculated using Brüggeman formula [17] in 3D and 2D (corresponding either to small grains or to columns extending through the whole film thickness). A correlated microstructure, in which the amorphous component always coats the crystalline grains, is described by the Maxwell-Garnett formula [18], which is commonly used for cermet composites with low volume fractions of metal but which predicts the transition close to $100 \%$ crystallinity (see the line and arrow labeled MG in Fig. 2). The actual materials usually correspond to a compromise between the random and fully correlated microstructural models. Corresponding formula for materials with partially correlated microstructure was proposed by Wood and Ashcroft [19]. In this case it is assumed that the material consists of a mixture of the more resistive phase (a-Si:H in our case) and of conductive regions (in our case Large Grains) coated by a "tissue" (in our case LGBs). The free parameter of the model is the thickness of the coating tissue relative to the grain diameter.

As for the calculation of the Wood-Ashcroft dependence in Fig. 2, we used the value of $18 \%$ of the structural unit for the volume of the LGB coating, which would correspond to the relative thickness of the LGB coating of approx. $6 \%$ of the grain radius. For the sake of simplicity, the value of the a-Si:H conductivity was used for the LGB component. The corresponding line (WA) in Fig. 2 shows that we can indeed model the transition occurring at $\sim 80 \%$ crystallinity as a result of the grains being coated by the more resistive tissue (LGB).

The main message from Figs. 1 and 2 and the discussion above is that microcrystalline silicon is not a random mixture of pure a-Si:H and pure $\mu \mathrm{c}-\mathrm{Si}: \mathrm{H}$ components and that the conductivity results require a presence of a resistive layer coating the crystalline grains, which we identify with the LGB - Large Grain Boundary discussed previously.

At or near the a-Si:H / $\mu \mathrm{c}-\mathrm{Si}: \mathrm{H}$ transition, where the crystallinity sharply increases (see for example Fig. 3a), we often observe the changes of the prefactor $\sigma_{0}$ and activation energy $E_{a}$, describing the thermal dependence of the dark conductivity around the room temperature (RT). The typical example of the changes is given in Fig. 3b) for the thickness series of the samples: upon the 
transition, the conductivity prefactor $\sigma_{0}$ dramatically decreases to below $100 \Omega^{-1} \mathrm{~cm}^{-1}$ and the activation energy $\mathrm{E}_{\mathrm{a}}$ decreases below $0.5 \mathrm{eV}$.

On the basis of AFM topography and other measurements [10], we interpret this as the formation of Large Grain Boundaries (LGB) due to dense arrangement of the Large Grains columns (aggregates of small grains). The basic idea of our model of transport in $\mu \mathrm{c}-\mathrm{Si}: \mathrm{H}$ is that LGBs consist of modified amorphous tissue into which most of the defects and $\mathrm{H}$ and possibly $\mathrm{O}$ atoms concentrate $[5,20]$, increasing the band gap of LGB.

To explain the features shown in Figs. 1-3 we have suggested the model based on the density of states (DOS) for the components present in the films and the transport path within the DOS as illustrated in Fig. 4. The scheme in the left shows the commonly accepted DOS for a-Si:H. The DOS for the isolated Large Grains of $\mu \mathrm{c}-\mathrm{Si}: \mathrm{H}$ in the center of Fig. 4 shows also the tail states due to the grain boundaries of the small grains. These two images are aligned according to the conduction band offset less or around $0.1 \mathrm{eV}$ and the valence band edge offset around $0.2-0.6 \mathrm{eV}$, corresponding to the mobility gap of $\mu \mathrm{c}-\mathrm{Si}: \mathrm{H}$ fluctuating in the range 1.5-1.1 eV for different microstructures [2123].

As we move from a-Si:H to a mixed material, the presence of small grains or isolated large grains and their smaller band gap represent the reason why the Fermi level $\left(\mathrm{E}_{\mathrm{F}}\right)$ moves up, leading to the decrease of $E_{a}$ seen in Fig. $3 b$ ) for the thicknesses smaller than $0.6 \mu \mathrm{m}$. Corresponding slow increase of the resulting conductivity with crystallinity can be seen in Fig. 1. At the same time, no changes are observed in the conductivity prefactor in Fig. 3b), which is an important confirmation that the transport path for electrons stays at the conduction band mobility edge.

Finally, the scheme in the right part of Fig. 4 shows the $\mu \mathrm{c}-\mathrm{Si}: \mathrm{H}$ with the densely packed Large Grains connected by grain tissue (Large Grain Boundaries) with the band gap higher due to the concentration of oxygen or hydrogen into LGBs. The drop of $\sigma_{0}$ below $100 \Omega^{-1} \mathrm{~cm}^{-1}$ and activation energy $\mathrm{E}_{\mathrm{a}}$ below $0.5 \mathrm{eV}$ indicates the down shift of the electron transport path, see the right scheme in Fig. 4, which now takes place through the tail states within the Large Grains and by hopping or tunneling through the LGB and/or a-Si:H tissue, see Fig. 5a). We have, however, never said that the conduction path for charge transport is fully and only through the LGB or a-Si:H tissue, see Fig. 5b), as stated by [6]! The LGBs need to be seen rather as the transport-limiting step which determines the resulting thermal behaviour of the conductivity.

Our model of transport is based on the existence of the third phase - the LGB - to explain the changes of the prefactor and activation energy upon the a-Si:H / $\mu \mathrm{c}-\mathrm{Si}: \mathrm{H}$ transition and the same conclusion has been drawn from the crystallinity value, at which the percolation threshold occurs.

In the following section we shall show that there is no conflict between our macroscopic conductivity [10-14] and microscopic C-AFM results [2], which was broadly discussed in [6].

\section{AFM results}

The two main experimental results of the work [6] measured by C-AFM were: 1) the observation (see Fig. 2 in [6]) of the conductive rings at the column boundaries (low $X_{c}$ sample, measured in a sandwich geometry) and 2) the fact that the expected conductive rings were not observed for $X_{c}$ $50 \%$ sample by coplanar C-AFM (similar to our schematic Fig. 6), because "no lateral percolation network of the columnar disordered tissue is completed" (see the text and Fig. 3 in [6]). We believe that both experimental results were related to oxidation when 6-10 V is used in C-AFM, see below.

Here we present the C-AFM results on a $\mu \mathrm{c}-\mathrm{Si}: \mathrm{H}$ sample (prepared at $100^{\circ} \mathrm{C}$ by $13.56 \mathrm{MHz}$ PECVD with the dilution $\mathrm{r}_{\mathrm{H}}=\left[\mathrm{H}_{2}\right] /\left[\mathrm{SiH}_{4}\right]=25$ ), with similar $\mathrm{X}_{\mathrm{c}} \sim 50 \%$ as in [6], i.e., corresponding to the mixed phase $\mu \mathrm{c}-\mathrm{Si}: \mathrm{H}$. The standard "macroscopic" coplanar contacts with the gap changing from 0.2 to $2 \mathrm{~mm}$ have been prepared on a $5 \times 10 \mathrm{~mm}$ glass substrate and used to measure the coplanar conductivity, which for this sample turned out to be $\sigma_{\mathrm{D}}=8.10^{-8} \Omega^{-1} \mathrm{~cm}^{-1}$.

Using the same sample we have performed the C-AFM measurements. The current was collected laterally by a lithographically defined gold contact to which the voltage of $-1.4 \mathrm{~V}$ was applied with 
respect to the grounded AFM tip. Several positions of the AFM field of view were chosen, at the gold contact edge and at distances up to $500 \mu \mathrm{m}$ from it, see the scheme in Fig. 6. Selection of the three current maps within the field of view $2 \times 2 \mu \mathrm{m}^{2}$ at the tip - electrode distances of 0,250 and 500 $\mu \mathrm{m}$ are shown in Fig. 7.

A surprising observation is that in the left current map in Fig. 6 the average current observed on the grains almost does not depend on the distance from the contact edge. We have expected that the current measured on the grains in contact with the Au electrode would be much higher but this was not the case. This apparent paradox is probably due to the thin native oxide layer which was formed on the surface of $\mu \mathrm{c}-\mathrm{Si}: \mathrm{H}$ in air.

The fact that the contrast of the scan even at the distance $500 \mu \mathrm{m}$ from the electrode looks similar to the one at $0 \mu \mathrm{m}$ may also seem rather surprising. But note that the maximum current, corresponding to the white color, decreases with the distance, as expected due to the current collection to the electrode aside from the tip. To quantify the changes of the current we had to average out the current noise due to the intermittent contact of the scanning tip. The current averaging was carried out along many line profiles over the grains (see Fig. 8a) and the resulting currents are plotted as a function of the tip-contact distance in Fig. 8b. The decrease of the current approximately corresponds to the additional film resistance expected for the observed film conductivity $\left(8.10^{-8} \Omega^{-1} . \mathrm{cm}^{-1}\right)$ which the current has to overcome on its way to the contact. The precise fit of the curve in Fig. $8 \mathrm{~b}$ is difficult due to geometry (tip versus coplanar electrode, see Fig. 6) and unknown transition resistances (tip - native oxide,...).

The clearly expressed contrast between the columns and a-Si:H tissue even for the scan at $500 \mu \mathrm{m}$ is given by the fact that on a-Si:H tissue the tip represents the real point contact (see Fig. 6) while on the grains it contacts more conductive Si columns, which then pass the current to the a-Si:H layer through a substantially increased area. In other words, the difference of the current level on the grains and on the amorphous phase can be understood as the difference of the a-Si:H spreading resistance of the tip - a-Si:H and the tip - grain - a-Si:H junctions. At the same time this is another proof that the $\mathrm{Si}$ columns are highly conductive in the whole volume, not just at the column boundaries.

The proposal of the main transport route in undoped $\mu \mathrm{c}-\mathrm{Si}: \mathrm{H}$ through the column boundaries [6] was experimentally based mainly on the C-AFM observation of the conductive rings at the column boundaries (Fig. 2 in [6]). In [24] the oxidation of $\mu \mathrm{c}-\mathrm{Si}: \mathrm{H}$ has been studied in detail, showing that for positive voltages above $2 \mathrm{~V}$ during the AFM measurement the oxide layer is formed by tip induced LAO (Local Anodic Oxidation) [25], usually much thicker than the native one, complicating any C-AFM measurements (see also above). Much higher voltages, from 6 to $10 \mathrm{~V}$, have been used in [6] .

In fact, we have been able to show directly that the sample oxidation resulting from LAO may lead to the observation of the conductive rings at the column boundaries. As an example Fig. 9 shows the C-AFM measured at the distance $50 \mu \mathrm{m}$ on the same sample as above. For $-1.4 \mathrm{~V}$, the usual picture (see also Fig. 7) is observed, with clearly expressed conductive columns, without the rings at the grain boundaries. For $+10 \mathrm{~V}$, the overall measured current decreased by an order of magnitude due to LAO formed oxide and concentrated mainly at the column boundaries, as in [6]. The fact that here we have used the coplanar contact for current collection, while in [6] the sandwich geometry has been used, is not important. The explanation why rings are formed exceeds the size of this paper and will be published elsewhere [26]. Results similar to those described above have been observed also on samples prepared under different conditions.

\section{Discussion}

We believe that both our macroscopic and microscopic coplanar measurements demonstrated that the transport proceeds through the more conductive crystalline $\mathrm{Si}$ grains. We do not see evidence for the tissue representing the main transport path in undoped $\mu \mathrm{c}-\mathrm{Si}: \mathrm{H}$, as suggested in [6]. 
This, however, does not exclude the possibility that, namely in the sandwich geometry, local point short-circuits might be present within the grain boundary tissue. These have been indeed observed at selected column boundaries for low quality $\mu \mathrm{c}-\mathrm{Si}: \mathrm{H}$ solar cells in [24] and attributed to local increase of the number of defects and oxygen concentration, which can play both alloying as well as doping role. Moreover, a correlation of the number of dopants and defects is well known [27]. The role of oxygen is very complex, causing inhomogeneity and/or even substitution of $\mathrm{H}$ in its role of the dangling bond passivation and it is discussed elsewhere [28].

Here we have to mention one point, which could have led to the misinterpretation of our model of transport and experimental results by the authors of [6] and also in some points in [24]. The problem appears to be the following: in our model we say that the LGBs are formed whenever the prefactor $\sigma_{0}$, deduced from the temperature dependence of $\sigma_{\mathrm{D}}$, decreases below $100 \Omega^{-1} \mathrm{~cm}^{-1}$ and at the same time the activation energy $\mathrm{E}_{\mathrm{a}}$ decreases below $0.5 \mathrm{eV}$. The decrease of the prefactor $\sigma_{0}$ and activation energy $E_{a}$, however, can lead to either the decrease or increase of the measured conductivity, depending on the temperature at which the measurement is performed, see schematic Fig. 10. At high temperatures, the conductivity decreases due to the decrease of prefactor $\sigma_{0}$ while at low temperatures (and in our specific case also at RT) conductivity increases due to the decrease of $\mathrm{E}_{\mathrm{a}}$. Nevertheless, the increase of the measured RT conductivity is not an indication that the LGBs represent the more conductive component of the films [6].

On the contrary, we believe that when LG (columns) are formed, the LGBs represent a new form of tissue, into which hydrogen, probably oxygen and defects concentrate. The increased content of $\mathrm{H}$ and $\mathrm{O}$ increases the mobility band gap and the potential barriers are formed, blocking the transport at the conduction band edge. At the same time, the number of defects in LGBs is relatively high and a new transport path in the DOS scheme opens (see Fig. 4, right part), leading through the column tail states within the LG and through the defects in LGBs by hopping or tunneling. Opening of this path is manifested in changes of $\sigma_{0}$ and $\mathrm{E}_{\mathrm{a}}$, but it is still the transport through a phase much more resistive than the grains and it takes place only in the places where LGs are in a near contact (see Fig. 5a). We believe that transport only through the LGBs (see Fig. 5b) is, at least for coplanar geometry, critically limited by the geometrical factor, ratio of LGBs length and cross-section.

Recently, fluctuation-induced tunneling [29] has been used to explain the low temperature dependence and saturation of $\sigma_{\mathrm{D}}$ of some $\mu \mathrm{c}-\mathrm{Si}: \mathrm{H}$ samples (including our old results). This model assumes, as well as our model, the presence of the potential barriers between the grains and a tunneling channel through the barriers, instead of our hopping. However, it is very difficult to accept the idea [29] that fluctuating barrier is due to the a-Si:H and c-Si conduction band offset, with the average value of $0.36 \mathrm{eV}$ ! Even the references given by the authors of [29] and many others $[21,22]$ clearly indicate that the conduction band offset is less or around $0.1 \mathrm{eV}$. Having in mind that $\mathrm{O}$ in aSi:H can lead to band gap fluctuations [28], the potential barriers at our LGBs can fluctuate, which represents a very reasonable generalization of our model.

\section{Conclusions}

We have discussed our model of transport in $\mu \mathrm{c}-\mathrm{Si}: \mathrm{H}$ based on the idea that the main transport route is through the conductive crystalline Si Large Grains and the Large Grain Boundaries, the formation of which is indicated by the observed changes of the activation energy and conductivity prefactor. The model is further supported by the effective medium theories needed to describe the percolation threshold observed for many undoped thin Si film series at crystallinity $X_{c} \sim 70-80 \%$.

Generally, our coplanar conductivity results measured microscopically, with the help of C-AFM, and macroscopically, overall in the $\mathrm{nm}-\mathrm{mm}$ range, agree very well. We have also illustrated possible sources of error in the interpretation of the microscopic mapping of local current measured by AFM, namely that when high positive voltages (more than $2 \mathrm{~V}$ ) are used in C-AFM in air. The overall current decreases due to tip induced oxidation and more conductive grain boundaries are artificially emphasized. 
As a final note we want to mention that although photoconductivity is far more important than the dark conductivity for photovoltaic solar cells, the understanding of the role of LGB is still more than relevant. Photoconductivity strongly depends on the number of defects and because they concentrate to LGBs it is important to have a simple tool to detect and prevent formation of the LGBs. That is precisely why our model of transport and namely the empirical rule - drop of prefactor $\sigma_{0}$ and activation energy $\mathrm{E}_{\mathrm{a}}-$ are important.

\section{Acknowledgements}

This research was supported by AV0Z 10100521, LC510, LC06040, IAA1010413, KJB100100512 and KAN400100701 projects.

One of the authors (JK) added the following personal memory: During my stay in Cambridge (1977-78) I also visited the laboratory and the home of Walter Spear in Dundee and this visit strongly influenced my following scientific carrier. I changed the subject from chalcogenide glasses to the quickly developing field of amorphous silicon and with the support of Walter, giving us advice and sending samples, developed the new Time of Flight set-up in Prague. Since that time and even more after the $12^{\text {th }}$ ICALS in Prague we were in contact with Walter and Peter LeComber, too. On many occasions I greatly enjoyed the discussions with Walter on both scientific and non scientific subjects.

Even after his retirement we exchanged Christmas cards with long letters every year, the last one in December 2007, so I was really surprised and deeply sorry to hear about his death.

Looking back, I can think of only a very few people who could be so proud of not only influencing the basic science so deeply but also of having such a great practical impact on everybody's life. Walter's work undoubtedly formed a basis of the present flat panel LCD displays industry and even just now, writing this commemoration, I am using his results by watching the text on an LCD display. I am sure I will never forget Walter Spear.

\section{References}

[1] J. Meier, R. Fluckiger, H. Keppner, and A. Shah, Appl. Phys. Lett. 65, 860-862 (1994).

[2] Bohuslav Rezek, Jiř́i Stuchlík, Antonín Fejfar, and Jan Kočka, Appl. Phys. Lett. 74, 1475-1477 (1999).

[3] D. Will, C. Lerner, E.A. Shiff, W. Fuhs, and K. Lips, in Amorphous and Microcrystalline Silicon Technology - 1997 (Materials Research Society, San Francisco, n.d.), pp. 361-366.

[4] K. Lips, P. Kanschat, and W. Fuhs, Sol. Energy Mat. Sol. Cells 78, 513-541 (2003).

[5] F. Finger, J. Müller, C. Malten, R. Carius, and H. Wagner, J. Non-Cryst. Sol. 266-269, 511-518 (2000).

[6] D. Azulay, I. Balberg, V. Chu, J. P. Conde, and O. Millo, Phys. Rev. B 71, 113304-4 (2005).

[7] Jan Kočka, Antonín Fejfar, Ha Stuchlíková, Jiř́ Stuchlík, P. Fojtík, Tomáš Mates, Bohuslav Rezek, Kateřina Luterová, V. Švrček, and Ivan Pelant, Sol. Energy Mat. Sol. Cells 78, 493-512 (2003).

[8] Jan Kočka, Jiř́ Stuchlík, Ha Stuchlíková, V. Švrček, Petr Fojtík, Tomáš Mates, Kateřina Luterová, and Antonín Fejfar, Appl. Phys. Lett. 79, 2540-2542 (2001).

[9] Tomáš Mates, Paula C.P. Bronsveld, Antonín Fejfar, Bohuslav Rezek, Jan Kočka, J.K. Rath, and R.E.I. Schropp, J. Non-Cryst. Sol. 352, 1011-1015 (2006).

[10] Jan Kočka, Ha Stuchlíková, Jiř́i Stuchlík, Bohuslav Rezek, V. Švrček, Petr Fojtík, Ivan Pelant, and Antonín Fejfar, in Polycrystalline Semiconductors VI - Bulk Materials and Thin Films and Devices, edited by O. Bonnaud, T. Mohammed-Brahim, H.P. Strunk, and J.H. Werner (Scitech Publ., Uettikon Am See, Switzerland, 2001), pp. 213-224. 
[11] Tomáš Mates, Antonín Fejfar, I. Drbohlav, Bohuslav Rezek, Petr Fojtík, Kateřina Luterová, Jan Kočka, Ch. Koch, M. B. Schubert, M. Ito, K. Ro, and H. Uyama, J. Non-Cryst. Sol. 299-302, 767 - 771 (2002).

[12] Jan Kočka, Antonín Fejfar, Tomáš Mates, Petr Fojtík, K. Dohnalová, Kateřina Luterová, Jiří Stuchlík, Ha Stuchlíková, Ivan Pelant, Bohuslav Rezek, A. Stemmer, and M. Ito, Phys. Stat. Sol. (c) 1, 1097-1114 (2004).

[13] Jan Kočka, Tomáš Mates, Martin Ledinský, Ha Stuchlíková, Jiř́i Stuchlík, and Antonín Fejfar, J. Non-Cryst. Sol. 352, 1097-1100 (2006).

[14] Jan Kočka, Tomáš Mates, Ha Stuchlíková, Jiří Stuchlík, and Antonín Fejfar, Thin Solid Films 501, 107-112 (2006).

[15] Martin Ledinský, Ladislav Fekete, Jiří Stuchlík, Tomáš Mates, Antonín Fejfar, and Jan Kočka, J. Non-Cryst. Sol. 352, 1209-1212 (2006).

[16] K. Shimakawa, Journal of Non-Crystalline Solids 266-269, 223-226 (2000).

[17] D. A. G. Bruggeman, Annalen Der Physik 416, 636-664 (1935).

[18] Maxwell Garnett, J. C., Philosophical Transactions of The Royal Society A 203, 385-420 (1904).

[19] D. M. Wood and N. W. Ashcroft, Phil. Mag. 35, 269-280 (1977).

[20] Toshihiro Kamei and Takehito Wada, J. Appl. Phys. 96, 2087-2090 (2004).

[21] X. Xu, J. Yang, A. Banerjee, S. Guha, K. Vasanth, and S. Wagner, Appl. Phys. Lett. 67, 23232325 (1995).

[22] S. Hamma and P. Roca i Cabarrocas, Appl. Phys. Lett. 74, 3218-3220 (1999).

[23] B. E. Pieters, H. Stiebig, M. Zeman, and R. A. C. M. M. van Swaaij, J. Appl. Phys. 105, 044502-10 (2009).

[24] Zhenhua Shen, Tamihiro Gotoh, Mototaka Eguchi, Norimitsu Yoshida, Takashi Itoh, and Shuichi Nonomura, Jap. J. Appl. Phys. 46, 2858-2864 (2007).

[25] Didier Stiévenard and Bernard Legrand, Prog. Surf. Sci. 81, 112-140 (2006).

[26] A. Vetushka, A. Fejfar, M. Ledinsky, B. Rezek, and J. Kocka, Physical Review B submitted.

[27] Vikram L. Dalal and Puneet Sharma, Appl. Phys. Lett. 86, 103510-3 (2005).

[28] J. Kočka, Stuchlíková, H., Ledinský, M., J. Stuchlík, T. Mates, and A. Fejfar, Solar Energy Materials \& Solar Cells (2009).

[29] S. J. Konezny, M. N. Bussac, and Libero Zuppiroli, Appl. Phys. Lett. 92, 012107-3 (2008).

\section{Figure Captions}

Fig. 1 Room temperature dark conductivity $\sigma_{D}$ of several series of thin film silicon samples with structure changing from amorphous to microcrystalline phase as a function of crystallinity (solid line is a guide to the eye). The meaning of symbols is as follows: „, $8^{\prime \prime}$ - thickness series $\left(\mathrm{T}_{\mathrm{S}}=250{ }^{\circ} \mathrm{C}, \mathrm{r}_{\mathrm{H}}=\right.$ $\mathrm{H}_{2} / \mathrm{SiH}_{4}=21$ [10]), ,॰ $\left(\mathrm{T}_{\mathrm{S}}=40-250{ }^{\circ} \mathrm{C}, \mathrm{r}_{\mathrm{H}}=32 \quad[14]\right),,{ }^{-“}$ - temperature series $\left(\mathrm{T}_{\mathrm{S}}=35-200{ }^{\circ} \mathrm{C}, \mathrm{r}_{\mathrm{H}}=133 \quad[14]\right),, \forall^{\prime \prime}-$ high growth rate dilution series $\left(\mathrm{r}_{\mathrm{H}}=10-32, \mathrm{~T}_{\mathrm{S}}=250{ }^{\circ} \mathrm{C}\right.$ [13]. For comparison, the dashed line shows the experimental results for highly doped microcrystalline silicon, showing percolation transition at crystallinity $\mathrm{X}_{\mathrm{C}} \sim 33 \%$ [16].

Fig. 2 Comparison of the different effective medium theoretical models with the room temperature dark conductivity $\sigma_{D}$ of one of the thin film silicon sample series from Fig. 1 (dilution series). The lines are the results of the effective medium conductivity calculated using different mixing rules, schematically shown at the top, with the arrows marking the percolation transition. The mixing rules correspond to a random aggregate structures in 3 or 2 dimensions (corresponding to random grains or to random columns) calculated using Brüggeman effective medium theory [17] (BR), fully correlated microstructure in which crystallites are always coated by an amorphous layer (MG) 
Maxwell-Garnett theory [18] and a partially correlated microstructure calculated using WoodAshcroft formula (WA) [19].

Fig.3 a) The crystallinity for the thickness series of samples [7] and b) the dark conductivity prefactor $\sigma_{0}\left(,,,,-\right.$ right axis), activation energy $E_{a}(, \circ,,-$ left axis) for the same thickness series of samples [7]. The dashed line marks the values of the prefactor $\sigma_{0}=100 \Omega^{-1} \mathrm{~cm}^{-1}$ and $\mathrm{E}_{\mathrm{a}}=0.5 \mathrm{eV}$, i.e., our empirical rule for detecting the presence of the Large Grain Boundaries (LGB).

Fig. 4 Schematic illustration of the components present in the mixed phase silicon films. The components are present in various concentrations at different film crystallinity, increasing from left to right. Localized Density of States (DOS) are schematically marked and the transport paths through the transport limiting step are marked by arrows.

Fig. 5 Schematic picture of the different possible transport routes, see text.

Fig. 6 a) Scheme of the experiment in which the local sample conductivity is measured by AFM with a conductive cantilever and the current, spreading from the tip of the cantilever, is collected to the side electrode made by a lithographically defined evaporated layer of gold. b) Cross section of the side view in which the current flux lines are schematically shown at the gold contact and near the tip-surface junction at two different positions: on the amorphous surface and on a highly conductive microcrystalline column.

Fig. 7 Local current maps measured by AFM with a conductive cantilever using the applied voltage of $-1.4 \mathrm{~V}$ within the $2 \times 2 \mu \mathrm{m}$ field of view. As shown in Fig. 6, the current was collected through the film to a lithographically defined gold electrode at the distances indicated by the broken $\mathrm{X}$ axis. Note different current scales magnitudes shown as color scales. The arrow indicated in the right map marks the trace along which the line profile is shown in Fig. 8. About $300 \mathrm{~nm}$ Large Grains, composed of small crystallites, are evident.

Fig. 8 a) Line profile of the local current measured by AFM with a conductive tip along the arrow in Fig. 7 showing also the average local current measured on one of the grains. b) Dependence of the average current registered on the different grains at various distances from the edge of the current collecting gold electrode. The line is a guide to the eye.

Fig. 9 Maps of local currents observed by conductive AFM at two different voltages at the same location of the sample. The left map was measured first at the bias of $-1.4 \mathrm{~V}$ (applied on the current collecting electrode on the sample) where no oxidation of the sample surface is observed. The right map shows the map observed with the voltage of $+10 \mathrm{~V}$ at which the sample surface is oxidized by the measurement. Note that the average level of the current was reduced considerably and that the regions of the highest current are now located at the grain boundaries.

Fig. 10 Schematic illustration how the parallel decrease of conductivity prefactor $\sigma_{0}$ and activation energy $\mathrm{E}_{\mathrm{a}}$ can decrease or increase the measured conductivity, depending on the selected temperature. 


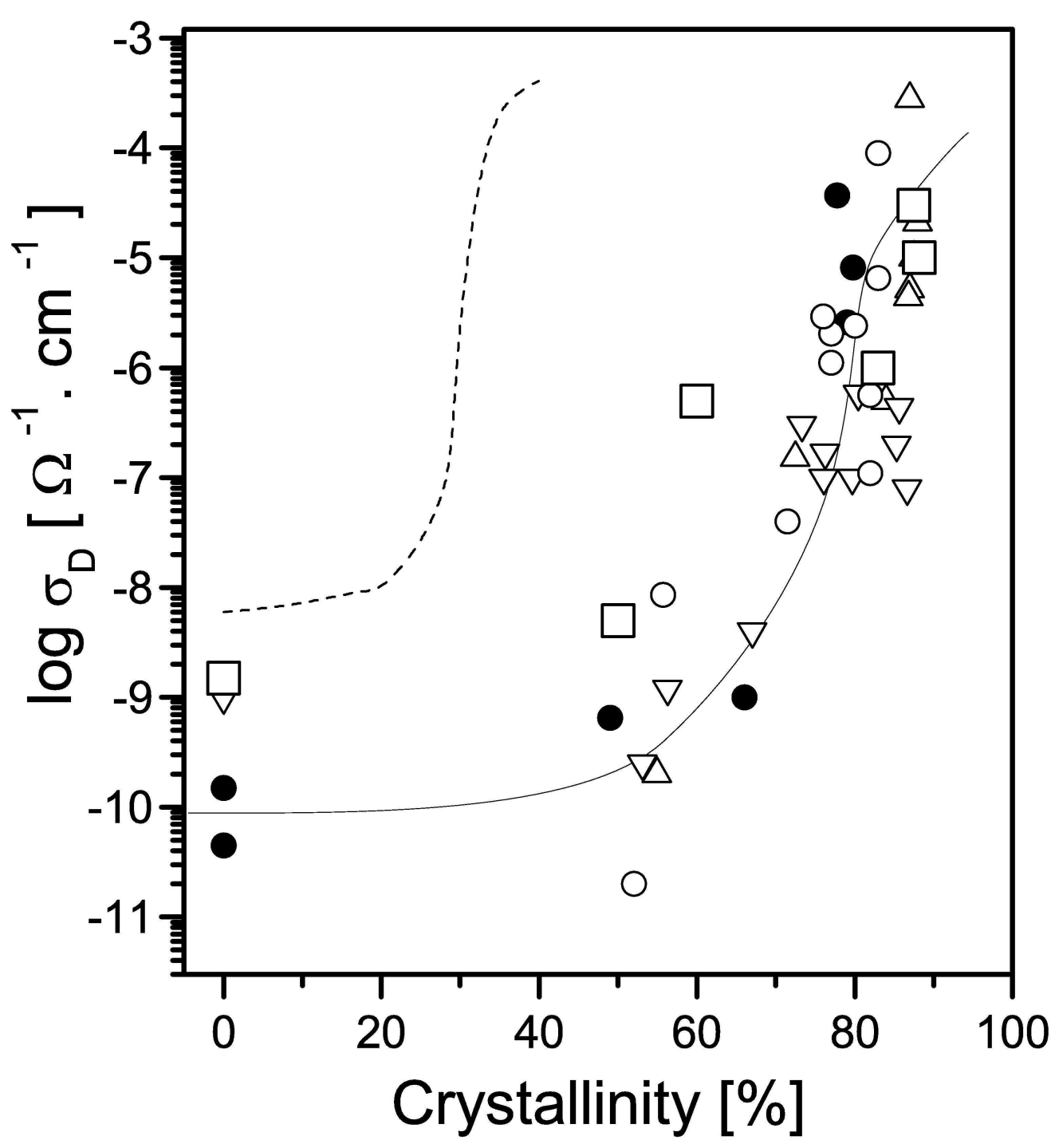

Fig. 1 Room temperature dark conductivity $\sigma_{D}$ of several series of thin film silicon samples with structure changing from amorphous to microcrystalline phase as a function of crystallinity (solid line is a guide to the eye). The meaning of symbols is as follows: " $\square$ " - thickness series (TS $=250{ }^{\circ} \mathrm{C}, \mathrm{r}_{\mathrm{H}}$

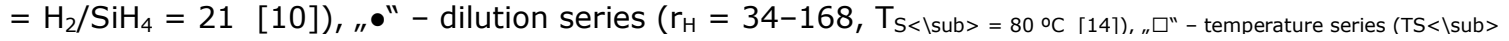
$=40-250^{\circ} \mathrm{C}, \mathrm{rH}<\mid$ sub $\left.>=32[14]\right), "{ }^{\circ "}-$ temperature series $\left(\mathrm{TS}<\mid\right.$ sub $>=35-200{ }^{\circ} \mathrm{C}, \mathrm{rH}<\mid$ sub $\left.>=133 \quad[14]\right), " \square "-$ high growth rate dilution series $\left(\mathrm{rH}<\mid\right.$ sub $>=10-32, \mathrm{TS}\langle\mid \mathrm{sub}\rangle=250^{\circ} \mathrm{C}$ [13]. For comparison, the dashed line shows the experimental results for highly doped microcrystalline silicon, showing percolation transition at crystallinity XC< $\langle$ sub $>\sim 33 \%[16]$. $129 \times 138 \mathrm{~mm}(600 \times 600 \mathrm{DPI})$ 


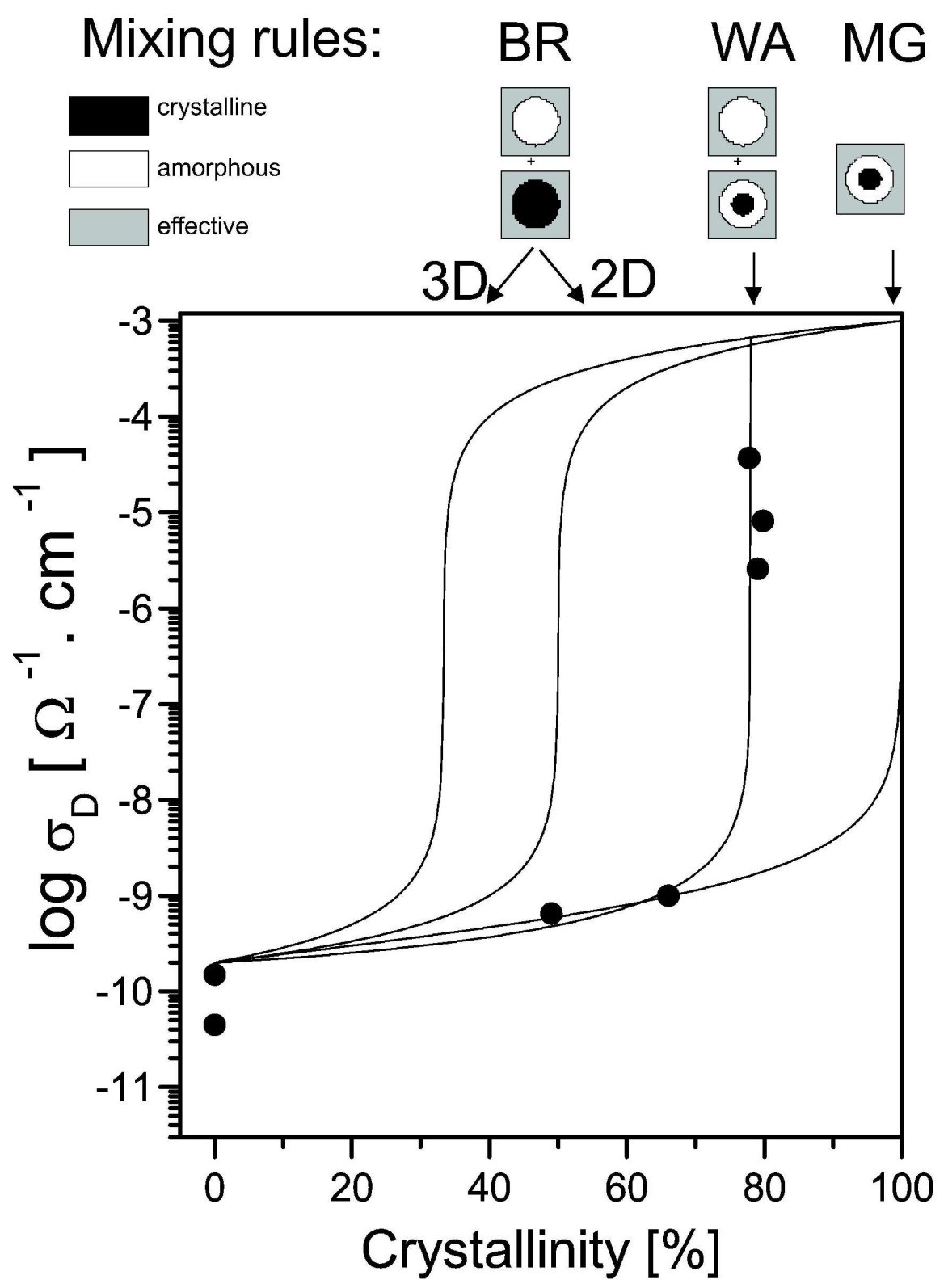

Fig. 2 Comparison of the different effective medium theoretical models with the room temperature dark conductivity $\sigma_{\mathrm{D}<\mid s u b>}$ of one of the thin film silicon sample series from Fig. 1 (dilution series). The lines are the results of the effective medium conductivity calculated using different mixing rules, schematically shown at the top, with the arrows marking the percolation transition. The mixing rules correspond to a random aggregate structures in 3 or 2 dimensions (corresponding to random grains or to random columns) calculated using Brüggeman effective medium theory [17] (BR), fully correlated microstructure in which crystallites are always coated by an amorphous layer (MG) $147 \times 201 \mathrm{~mm}(600 \times 600$ DPI $)$ 


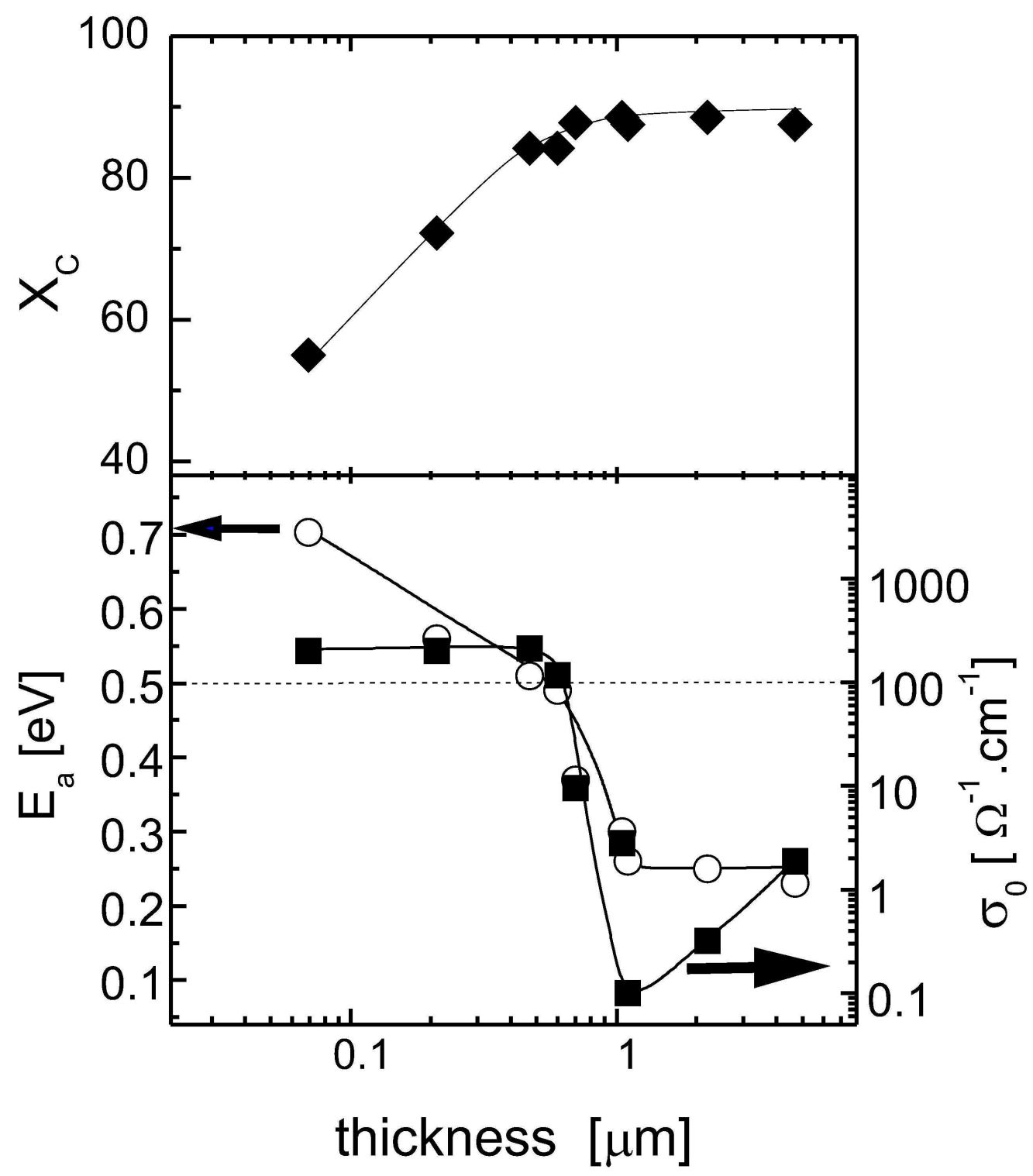

Fig. 3 a) The crystallinity for the thickness series of samples [7] and b) the dark conductivity

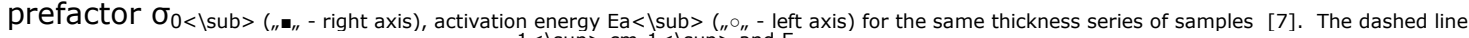
marks the values of the prefactor $\sigma 0<\mid$ sub $>=100 \Omega^{-1<\mid \text { sup }>\mathrm{cm}-1<\mid \text { sup }>\text { and } E}$ a $<\mid$ sub $>=0.5 \mathrm{eV}$, i.e., our empirical rule for detecting the presence of the Large Grain Boundaries (LGB). $107 \times 123 \mathrm{~mm}(600 \times 600 \mathrm{DPI})$ 

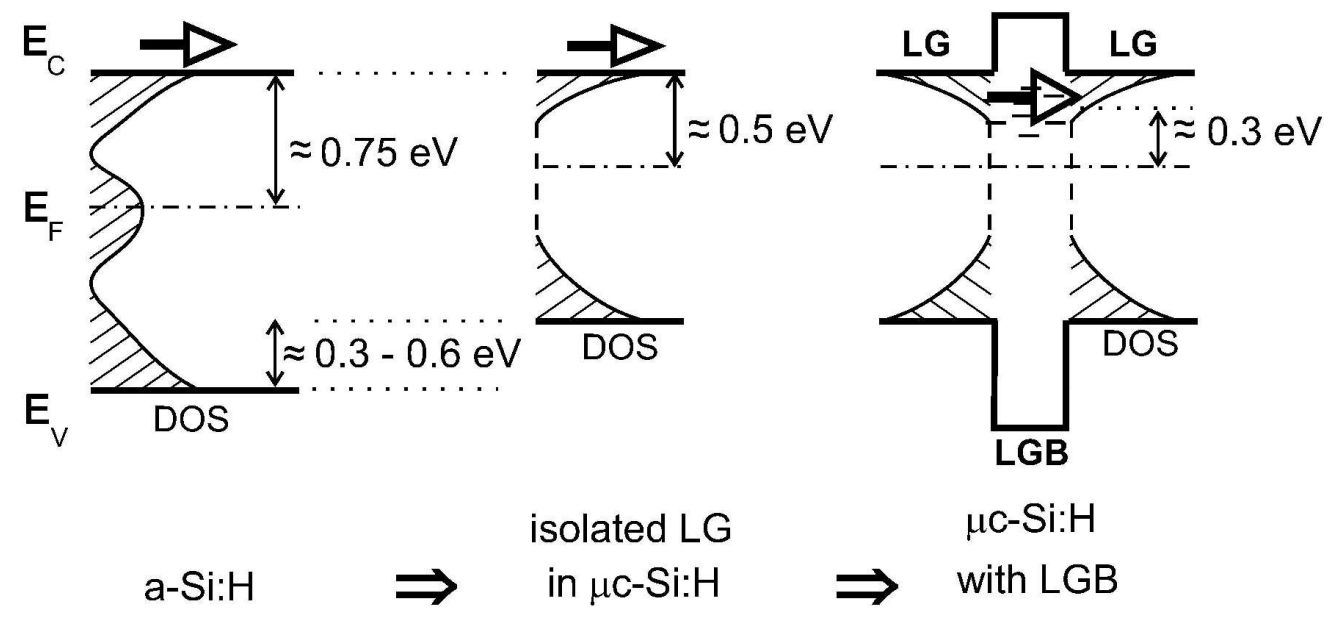

Fig. 4 Schematic illustration of the components present in the mixed phase silicon films. The components are present in various concentrations at different film crystallinity, increasing from left to right. Localized Density of States (DOS) are schematically marked and the transport paths through the transport limiting step are marked by arrows. $150 \times 68 \mathrm{~mm}(600 \times 600 \mathrm{DPI})$ 


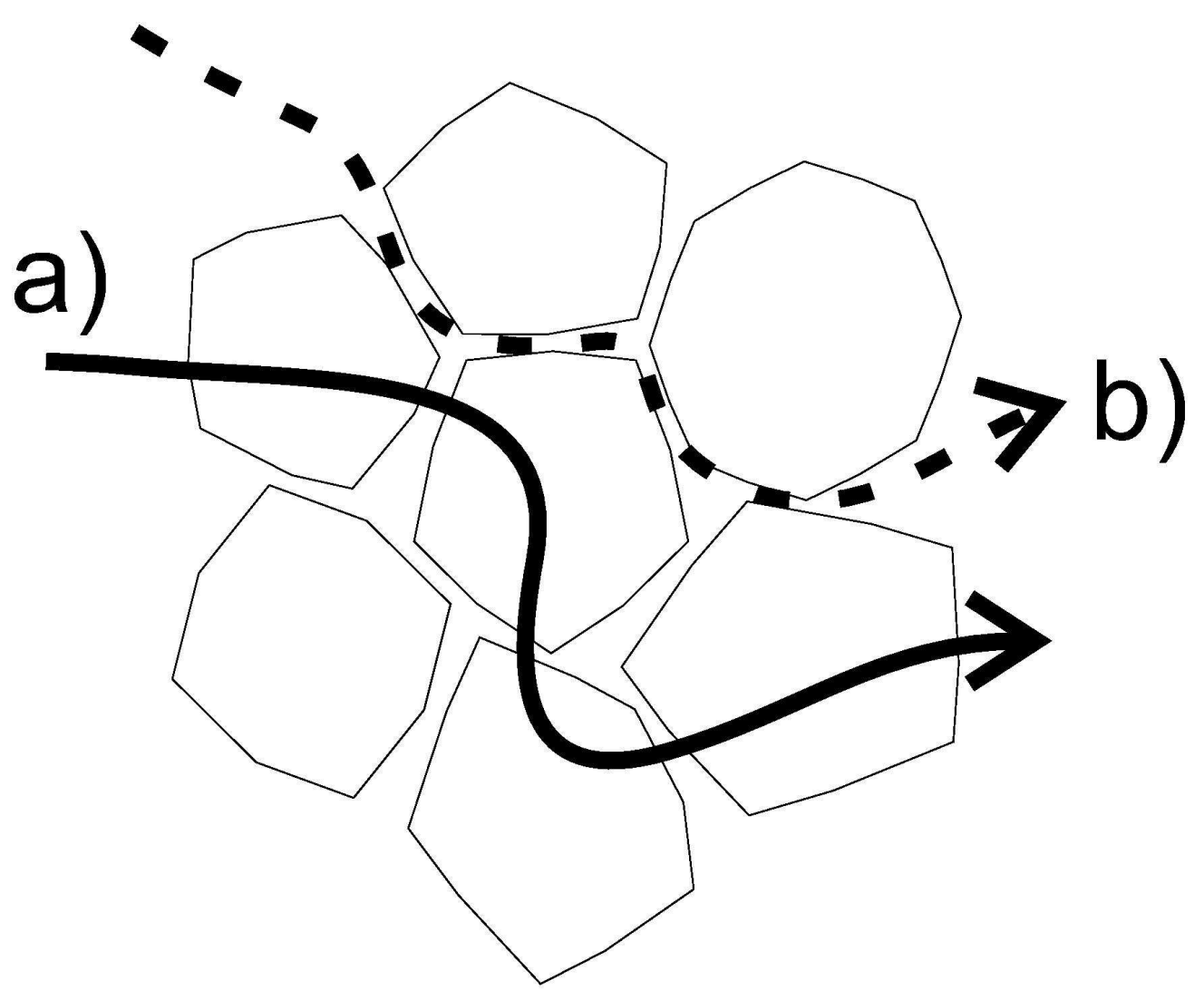

Fig. 5 Schematic picture of the different possible transport routes, see text. $74 \times 61 \mathrm{~mm}(600 \times 600 \mathrm{DPI})$ 


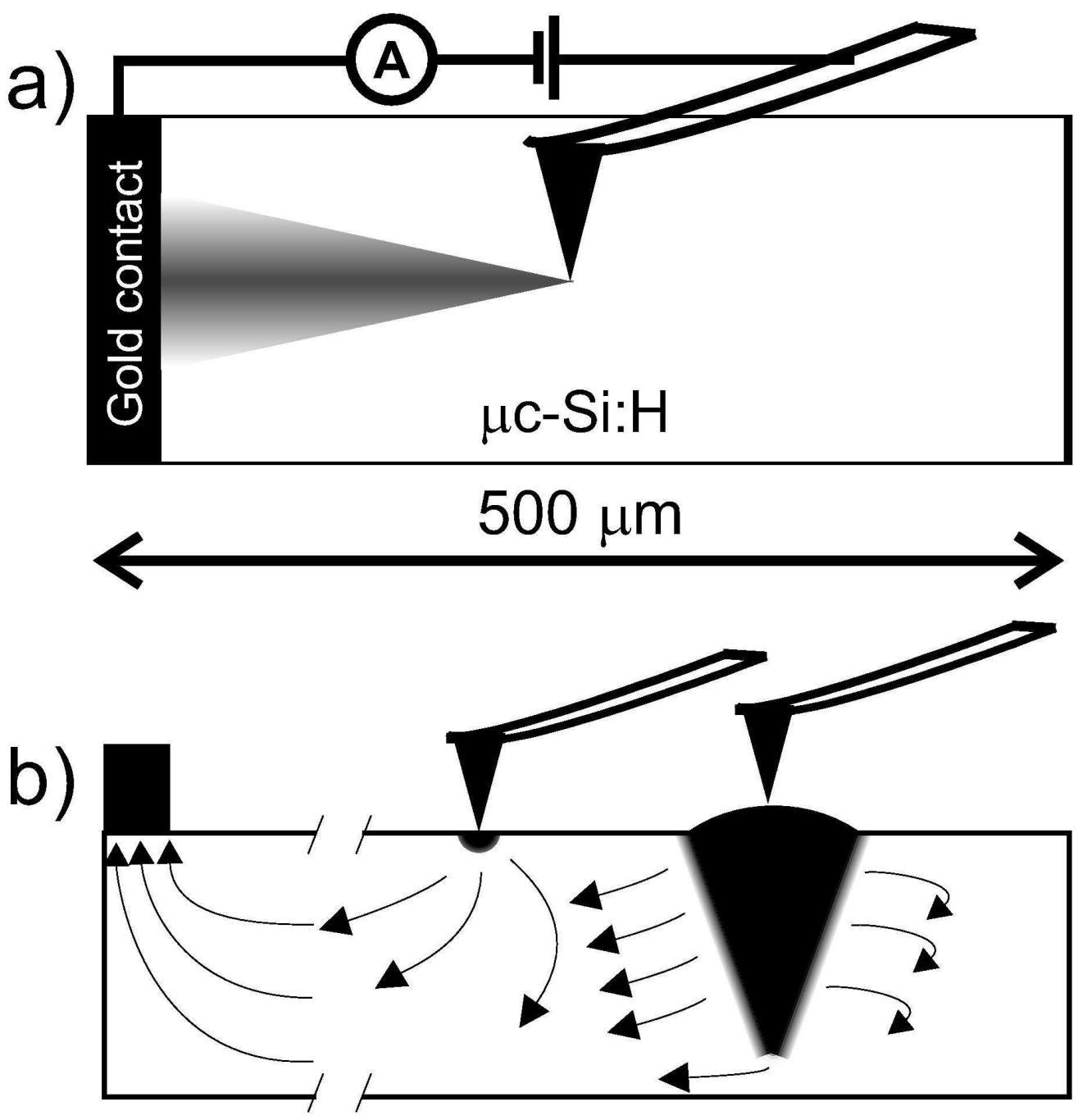

Fig. 6 a) Scheme of the experiment in which the local sample conductivity is measured by AFM with a conductive cantilever and the current, spreading from the tip of the cantilever, is collected to the side electrode made by a lithographically defined evaporated layer of gold. b) Cross section of the side view in which the current flux lines are schematically shown at the gold contact and near the tip-surface junction at two different positions: on the amorphous surface and on a highly conductive microcrystalline column.

$77 \times 80 \mathrm{~mm}(600 \times 600 \mathrm{DPI})$ 


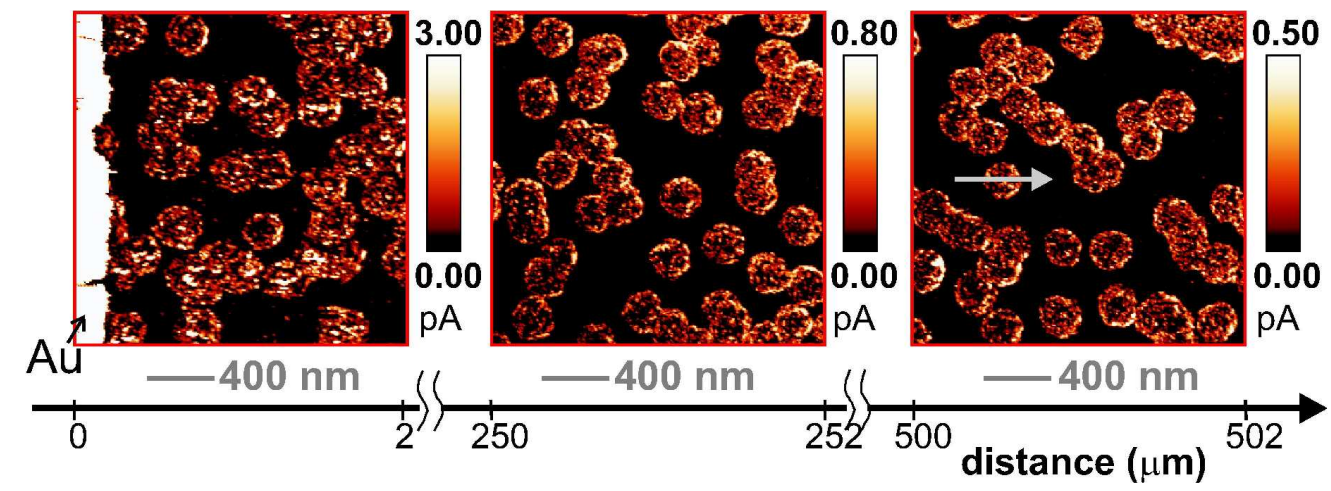

Fig. 7 Local current maps measured by AFM with a conductive cantilever using the applied voltage of $-1.4 \mathrm{~V}$ within the $2 \times 2 \mu \mathrm{m}$ field of view. As shown in Fig. 6 , the current was collected through the film to a lithographically defined gold electrode at the distances indicated by the broken $\mathrm{X}$ axis. Note different current scales magnitudes shown as color scales. The arrow indicated in the right map marks the trace along which the line profile is shown in Fig. 8. About $300 \mathrm{~nm}$ Large Grains, composed of small crystallites, are evident. $156 \times 57 \mathrm{~mm}(600 \times 600 \mathrm{DPI})$ 
a)

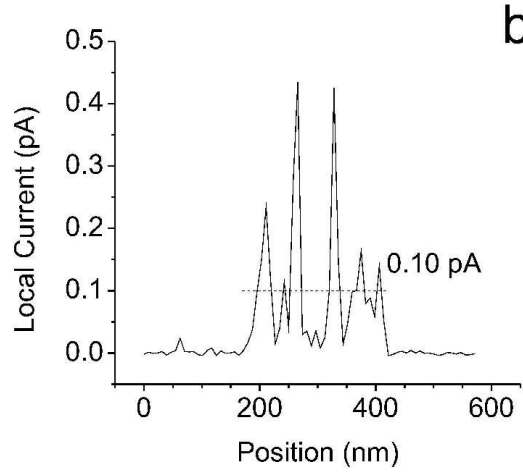

b)

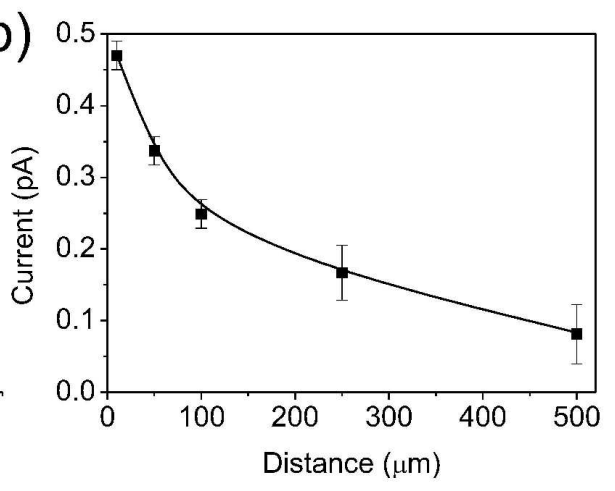

Fig. 8 a) Line profile of the local current measured by AFM with a conductive tip along the arrow in Fig. 7 showing also the average local current measured on one of the grains. b) Dependence of the average current registered on the different grains at various distances from the edge of the current collecting gold electrode. The line is a guide to the eye. $152 \times 63 \mathrm{~mm}(600 \times 600 \mathrm{DPI})$ 

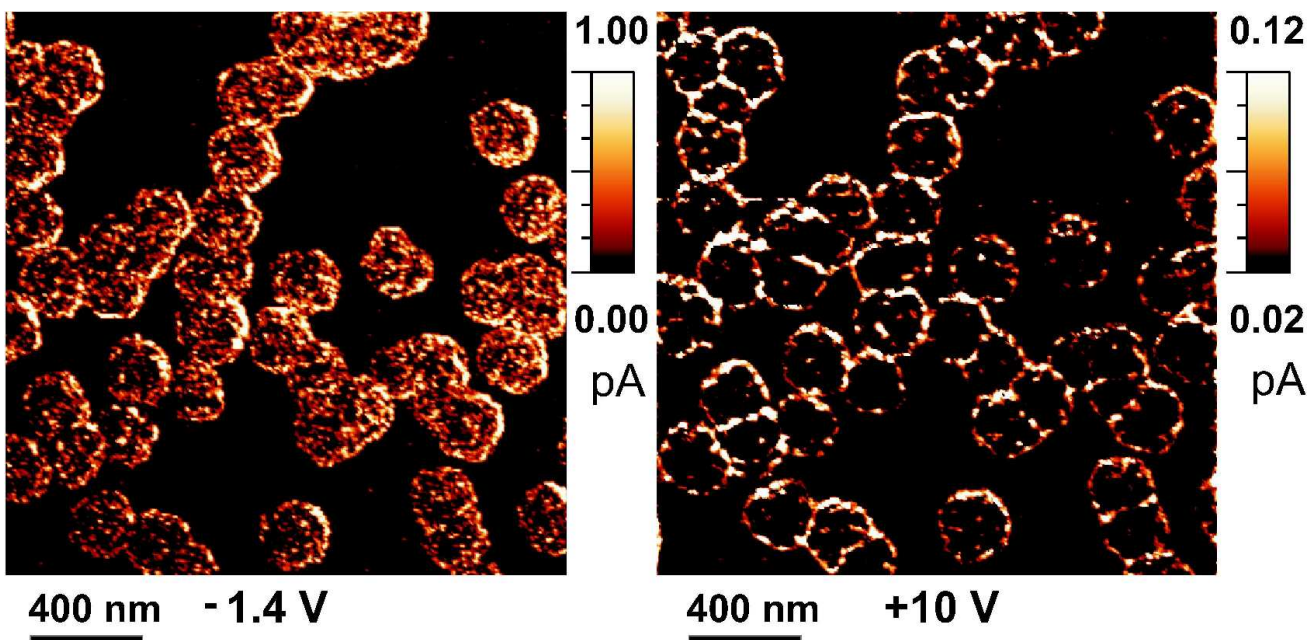

Fig. 9 Maps of local currents observed by conductive AFM at two different voltages at the same location of the sample. The left map was measured first at the bias of $-1.4 \mathrm{~V}$ (applied on the current collecting electrode on the sample) where no oxidation of the sample surface is observed. The right map shows the map observed with the voltage of $+10 \mathrm{~V}$ at which the sample surface is oxidized by the measurement. Note that the average level of the current was reduced considerably and that the regions of the highest current are now located at the grain boundaries. $142 \times 68 \mathrm{~mm}(600 \times 600 \mathrm{DPI})$ 


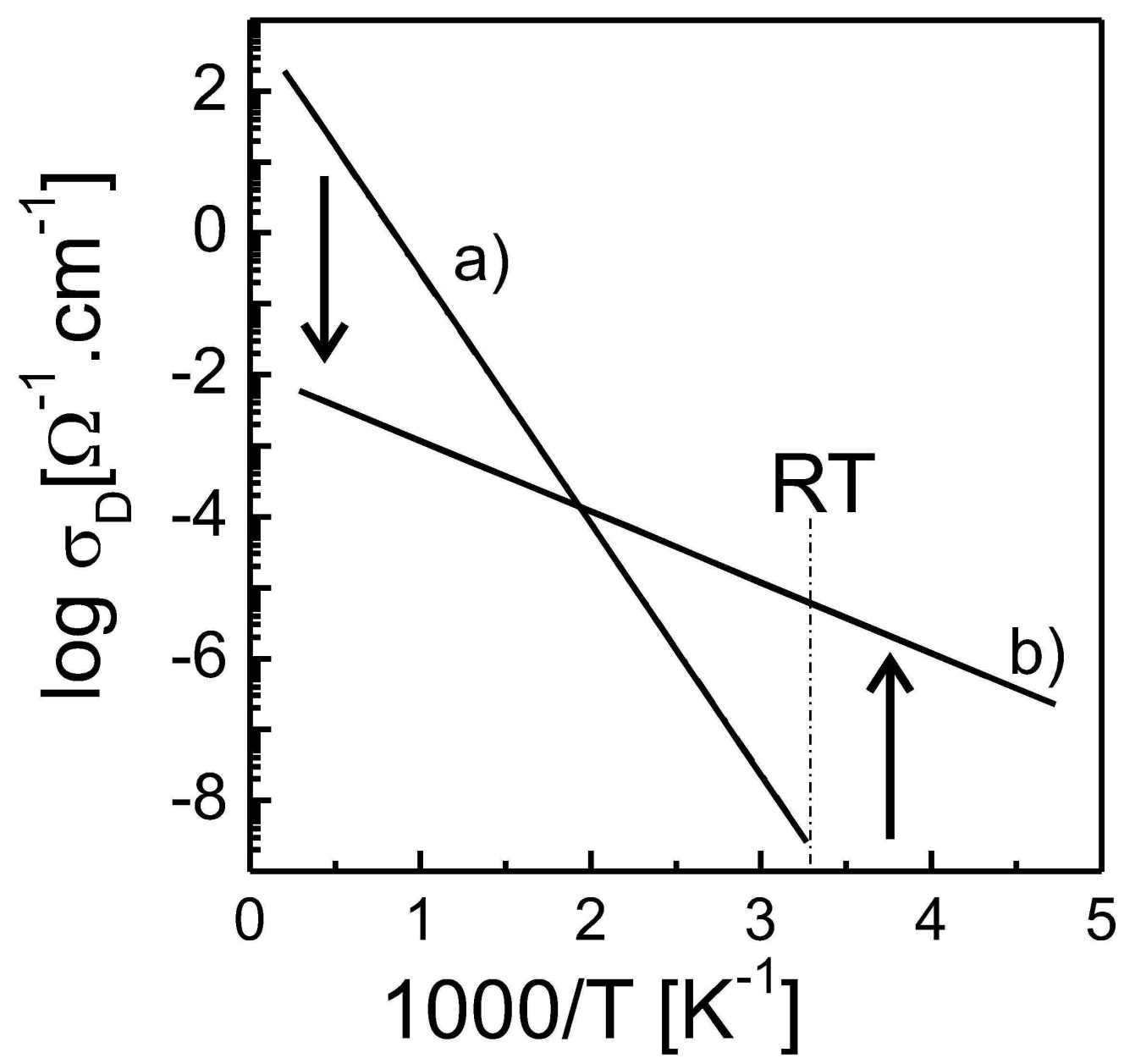

Fig. 10 Schematic illustration how the parallel decrease of conductivity prefactor $\sigma_{0<\backslash s u b>\text { and activation }}$ energy $\mathrm{Ea}<\mid$ sub $>$ can decrease or increase the measured conductivity, depending on the selected temperature.

$97 \times 92 \mathrm{~mm}(600 \times 600 \mathrm{DPI})$ 